\title{
Estado, sociedade civil e a política de interiorização da universidade na Amazônia
}

State, civil society and the university of assimilation policy on Amazon

Maria do Socorro Coelho - Doutora em Educação pela Pontificia Universidade Católica/ PUC/SP e pós-doutorado pela Universidade do Minho - Portugal; professora adjunta IV da Universidade Federal do Pará (UFPA), FAED/ICED/UFPA. E-mail: socorrocoelho@ gmail.com

\section{Resumo}

Esta investigação tem como objetivo demonstrar como se efetivou a relação entre Estado e sociedade civil na concepção e implementação da Política de interiorização das funções da Universidade, em especial da UFPA, para a zona rural da Amazônia. Utilizouse como fonte a pesquisa bibliográfica e documental. Concluiu-se ser possível levantar a hipótese explicativa de que a origem da política de interiorização das Universidades da Amazônia tem seu início no Estado desenvolvimentista e, em segundo momento, situa-se no bojo da "Nova República" com os Projetos Norte de Interiorização (PNI).

\begin{abstract}
This research aims to demonstrate how the relationship between State and civil society was effected considering the designing and the implementation of the Internalization Politics of the functions related to the University, in special the case of Universidade Federal do Pará (UFPA), looking at the Amazon rural side. It was used as source the survey of literature and written documents. It was concluded that it is possible to raise the hypothesis that the origin of the politics' internalization of Universities of the Amazon comes from the developmental state and than lies at the core of the "New Republic" with North Projects of Internalization.
\end{abstract}

\section{Palavras-chave}

\section{Keywords}

Estado. Sociedade civil. Interiorização da Universidade. Amazônia.

State. Civil society. Internalization. Amazon 


\section{INTRODUÇÃO}

Este estudo tem como objetivo apresentar uma análise sobre a atuação do Estado na Amazônia e o papel da sociedade civil no processo de implementação da política de interiorização da Universidade Federal do Pará (UFPA). A análise parte da seguinte questão: Como se efetivou a relação entre Estado e sociedade civil na concepção e na implementação da política de interiorização das funções da Universidade para a zona rural da Amazônia? No caminho metodológico utilizaram-se fontes e instrumentos de procedências diversificadas, como pesquisa bibliográfica e documental.

A pesquisa bibliográfica contemplou uma revisão teórica das categorias estado e sociedade civil. Os documentos escritos foram examinados a partir de leituras sequenciais e analisados detalhadamente, com o objetivo de identificar no texto categorias, contextos e situações que ajudassem a responder a questão levantada. Entre os documentos que resguardam informações importantes para a construção deste estudo, destacam-se Projetos Norte de Interiorização das Universidades Federais da Amazônia, o Plano Nacional de Extensão Universitária, a Constituição Federal de 1988, a LDB 9394/96 e a Emenda Constitucional n. ${ }^{\circ} 14$.

Inicialmente analisou-se a categoria sociedade civil, destacando as diversas compreensões e o uso indiscriminado desta. Em seguida, apresentou-se o estudo sobre o Estado e a sociedade civil no Brasil, tendo como cenário o período do regime militar e a origem da política de interiorização da UFPA; o recorte histórico (regime militar) foi mantido, no qual são demonstradas as reformas no âmbito educacional e o surgimento das primeiras experiências de interiorização da Universidade na Amazônia.

\section{ESTADO E SOCIEDADE CIVIL}

As políticas públicas são ações desenvolvidas pelo Estado ou por instituições não estatais destinadas a todas as esferas da sociedade. É importante ressaltar que se considera o Estado como ator principal e o responsável precípuo na elaboração, execução, acompanhamento e avaliação da eficiência das políticas no âmbito social.

Os canais de controle de uma política social por parte da população e a transparência das ações do Estado dependem da vinculação entre este e a sociedade civil. O grau desta relação poderá refletir na estrutura estatal os 
desejos de democratização, assim como poderá restringir ou ampliar o alcance e o controle das políticas públicas por parte da sociedade.

É importante ressaltar que a inadequação, e até mesmo conflitos, no uso indiscriminado de conceitos como sociedade civil, espaço público ou esfera pública. Uma hipótese explicativa para tal conflito conceitual, principalmente o de sociedade civil, pode estar na luta pela ampliação da oferta das políticas públicas e na reivindicação da população por mecanismos de controle sobre estas. Esta luta carrega, no seu interior, a diversidade de concepções e matizes de como se percebe a forma de relação travada entre o Estado e a sociedade civil.

Há uma heterogeneidade nos movimentos reivindicatórios e entre eles existem os movimentos comunitários aos quais as organizações não governamentais (ONGs) aderiram. Essas abrigam atualmente uma característica considerável: transformaram-se em importante canal de representação no Estado para a efetivação de políticas de cunho social. Há que se chamar atenção também para setores no interior da sociedade que defendem o mercado como ator a ser inserido em tal processo. Observou-se uma pluralidade de práticas e de conteúdo discursivo dos diversos atores sociais envolvidos nessa relação, o que pode provocar o que Duriguetto" (2007) identifica como "campo de tensão, ao se generalizar o uso dos conceitos, tendo como consequência as predominantes visões, percursos, formas e práticas diferenciadas de sociedade civil”.

Observando o caminho percorrido por vários autores que analisam as várias concepções sobre sociedade civil, encontram-se as formulações de Cohen e Arato (1992), que sistematizam um grande esforço sobre o conceito da categoria em questão. "Historicamente, a expressão sociedade civil é de origem aristotélica traduzida do Latim, denominada komonia politike, o que correspondia à comunidade pública de iguais (COSTA, 2002, p. 36 apud COHEN; ARATO, 1992, p.84)". Nesta definição, sociedade e Estado estavam fundidos, visão esta que permaneceu até o século XVIII. Para esses autores, o conceito moderno de sociedade civil "surge no contexto das lutas democráticas de oposição ao autoritarismo dos partidos estatais do Leste Europeu, e também no processo de luta pela democratização da América Latina" (COHEN; ARATO, 2000).

No Brasil, a divulgação conceitual de sociedade civil está associada, segundo Sérgio Costa (2002, p. 55), "à resistência ao regime autoritário, cumprindo esta a função político-estratégica; em consequência, a expressão tornou-se atributo

\footnotetext{
Maria Lúcia Duriguetto é autora do trabalho intitulado Sociedade Civil e Democracia: Um Debate Necessário. Na referida obra, a autora recupera os conceitos de Sociedade Civil e Democracia e a articulação com projetos sociais desenvolvidos no Brasil a partir da transição democrática.
} 
do não-militar, abrindo divisor de águas com o Estado (militar)". Esta distinção deixou a categoria sociedade civil relegada ao segundo plano, sendo utilizada como oposição ao regime. Desta forma, culturalmente o conceito adquiriu o significado de que os interesses da sociedade não estavam representados no espaço público, mas sim ditados pelas diretrizes do Estado, ação esta reforçada pelo regime autoritário.

O movimento contra a ditadura militar representou uma clara inversão dessa tendência histórica, na medida em que se revelou portador de um projeto político desencadeador de amplo consenso social, tendo sido articulado inteiramente fora - na verdade em oposição ao - do Estado. O atual projeto de sociedade civil, expresso conceitualmente na demarcação mais precisa dessa categoria, representa a continuidade do processo de desacoplamento da sociedade civil do Estado (Ibidem, p. 61).

O regime militar no Brasil atravessou a década de 1970 em pleno desenvolvimento, atingindo o seu esgotamento na década de 1980 caracterizada pela efervescência política da sociedade civil, culminando com eventos internacionais que transformaram a história mundial com a queda do socialismo no Leste Europeu e a crise do Estado de Bem-Estar Social. Tais fatos demonstraram a reflexão sistematizada por Gramsci de que hegemonia não é apenas uma prerrogativa do Estado, e sim pode ser conquistada pelos movimentos sociais. A ponderação feita por este autor inaugura, na ciência política brasileira, uma nova forma de abordar o conceito de sociedade civil.

Este estudo supõe um conceito de sociedade civil que traz a ideia de liberdade ante o Estado, ao mesmo tempo resguardando as tensões e os conflitos gerados por interesses existentes no sistema social. Tais interesses, muitas vezes, têm posições opostas ao ideal de participação democrática, solidariedade e, outras vezes, buscam o fortalecimento das relações no âmbito da dimensão privada (econômico), fortalecendo o projeto burguês do Estado moderno. Assim, a reflexão baseada no conceito de Gramsci reconhece que o Estado e a sociedade civil estão no mesmo espaço, ou seja, na superestrutura,

[...] o que pode ser chamado de sociedade civil (isto é, o conjunto de organismos chamados comumente de privados) e o da sociedade política ou Estado, que corresponde à função de hegemonia que o grupo dominante exerce em toda a sociedade é aquela de domínio direto ou de comando, que expressa no Estado e no governo jurídico. (GRAMSCI, 1988, p.10).

O conceito acima evidencia o vínculo de Gramsci com o campo marxista, apesar de este não trabalhar com o mesmo conceito de sociedade civil contido 
nas elaborações teóricas de Marx, que o situa na infraestrutura econômica. Ele recorre às análises de Marx, mas dá um novo significado a elas.

Em Cadernos do Cárcere (1989), Gramsci assinala que a estrutura e a superestrutura, apesar de manterem unicidade, resguardam autonomia frente à realidade. Em Marx, a sociedade civil é o lugar onde se travam as relações de ordem econômica, de produção e reprodução da base material, no qual acontece o intercâmbio concreto entre os homens.

Para Gramsci, a sociedade civil é o lugar onde se situam os sindicatos, as associações políticas e culturais às quais denomina organismos privados para diferenciá-las do Estado e seu poder político. Ele pensa na relação entre sociedade civil e Estado a partir do próprio Estado, mas ambos, Marx e Gramsci, não percebem a sociedade civil somente como o reino do consenso, da democracia plena:

[...] a história da sociedade civil, para Gramsci, é a história do domínio de alguns grupos sociais sobre outros, sendo a trama da hegemonia feita sempre, também, de subordinação, corrupção, exclusão do poder, é a história da luta de classes. (LIGUORI, 2007, p. 46).

A reflexão aqui exposta rejeita a concepção restrita de Estado e, como consequência, uma sociedade civil limitada, concepção formulada inicialmente por Marx e Engels, que consideram o Estado como o poder político organizado da classe dominante para garantir seus interesses, um comitê gerenciador dos negócios da burguesia ${ }^{2}$. Neste trabalho, o Estado foi visualizado como aquele que tem um papel ampliado, considerando as formulações sistematizadas por Gramsci sobre o Estado moderno.

Segundo Brandão Junior e Medeiros (1990), a concepção restrita de Estado é também denominada de dicotômica, pois nela este é visto como exterior aos movimentos sociais, concepção que sofreu forte influência de Hegel, mas é do raio de ação do Liberalismo e do Leninismo que esses autores fortificam essa análise.

O liberalismo via no Estado um conjunto de instituições neutras e exteriores à sociedade e, exatamente por ser neutro e exterior podia arbitrar interesses e preferências de uma forma plural e democrática. $\mathrm{O}$ Leninismo, por sua vez, via no Estado, uma essência burguesa que deveria ser tomada e substituída por outra essência, a proletária. A sociedade deveria organizar-se fora do Estado para tomá-lo. (BRANDÃO JUNIOR; MEDEIROS, 1990, p. 19).

2 A esse respeito, ver Ideologia Alemã (1993) e Manifesto do Partido Comunista, de Karl Marx e F. Engels (1998). 
A reinterpretação gramsciana introduz o conceito de Estado Integral (sociedade civil + sociedade política), o que para Brandão Junior e Medeiros significa "a redescoberta da ideia Weberiana da imbricação dialética entre estruturas de autoridades e estrutura de solidariedade vão permitir a crítica à visão dicotômica do Estado" (Ibidem, p. 19).

Desta forma, Gramsci não eliminou o caráter de classe e repressor do Estado, mas acrescentou novas características às apreciações marxistas e criou um novo conceito de Estado, fundindo sociedade civil e sociedade política no interior da superestrutura.

Para Gramsci, é na sociedade política que a classe dominante mantém seus aparelhos repressivos, seja pela força ou por intermédio da legislação. Para Carlos Nelson Coutinho, a originalidade de Gramsci está na ampliação do conceito de Estado. O Estado não é mais apenas a representação dos interesses da burguesia,

[...] mas é também o resultado de um equilíbrio dinâmico e mutável entre classes dominantes e classes subalternas, em que essas últimas conseguem (ou podem conseguir) implantar posições de poder no seio dos aparelhos do Estado (COUTINHO, 1996, p. 64).

A reflexão aqui desenvolvida pautou-se na tese de que o Estado não é só um produto do autoritarismo, e a interiorização das Universidades na Amazônia é um exemplo disso, sua concepção brotou no interior do projeto educacional do regime militar, mas a sociedade civil e vários intelectuais da Universidade demonstraram sua força contrária à coesão contida na proposta educacional do projeto desenvolvimentista na região, dando novos rumos à política, acoplando outra concepção educacional que ao longo dos 25 anos dos Projetos Norte de Interiorização (PNI) vem disputando a hegemonia de um projeto de sociedade solidária e fraterna.

Essa visão de Estado mutável e dinâmico é denominada por Brandão Júnior e Medeiros (1990) perspectiva antinômica, a qual concebe o Estado com ação simultânea, ora como pacto de dominação, expressando os interesses de classe em dada correlação de força, e em outro momento configura-se em uma organização.

O Estado, para agir como árbitro ou mediador de conflitos, precisa se revestir de várias faces, em diferentes momentos ou conjunturas históricas; ele veste a face do consenso e, dependendo da necessidade, usa a face da força coercitiva. Quando o Estado representa os interesses de todas as frações do bloco do poder, está agindo, como diz Marx e Engel, como comitê executivo.

Uma segunda face diz respeito à de mediador de interesses de algumas frações do bloco do poder ou de algumas frações da classe subalterna, como procurador e representante dos interesses em conflito. A capacidade de perceber 
que em diferentes momentos predomina uma das referidas faces é o mérito da contribuição teórica dos que defendem a visão ampliada ou antinômica do Estado capitalista.

Ao observar o Estado brasileiro, é possível trabalhar com a hipótese de que o mesmo tenha autonomia relativa nas classes sociais, pois consegue representar ora a primeira, ora a segunda face fazendo com que sua ação não se restrinja a instrumento do bloco no poder.

\section{ESTADO E SOCIEDADE CIVIL NA AMAZÔNIA}

No Brasil, o regime militar estabeleceu uma relação entre a sociedade civil e o Estado a partir da dominação violenta, caracterizando-se pelo monopólio da força. No processo de resistência ao regime militar, entidades de classe e partidos de oposição buscaram alcançar o consenso social em torno de alguns objetivos, por intermédio de alguns atores sociais, que tinham formas de organização e poder de mobilização contestatória, objetivando uma sociedade democrática.

A existência de atores sociais em conflito e sua clara confrontação pública são elementos indispensáveis de uma sociedade civil forte e bem constituída. Podemos dizer que, em boa medida, são a sociedade civil. Geram a dinâmica indispensável em toda verdadeira democracia. (RESTREPO, 1990, p. 83).

Os movimentos sociais de oposição ao regime autoritário foram importantes para o esgotamento deste e se constituíram no que Restrepo (1990) denomina atores sociais coletivos, uma vez que foram sujeitos de suas ações, configuraram um novo espaço público com base política de sustentação sem haver a necessidade de porta-voz.

A ebulição política registrada nas décadas de 1970 e 1980 foi fruto dos movimentos sociais. Entidades organizadas, como a União Nacional dos Estudantes (UNE); sindicatos, como a construção da Central Única dos Trabalhadores (CUT); setores da Igreja Católica, com as Comunidades Eclesiais de Base (CEBs); Partido Comunista Brasileiro (PCB), Partido Comunista do Brasil (PC do B), o nascente Partido dos Trabalhadores (PT); Movimento de Alfabetização de Jovens e Adultos, com inspiração em Paulo Freire; Movimento dos Trabalhadores Sem Terra (MST) e outros. Tais entidades de classe tinham identidade democrática e representavam interesses populares organizados.

Para este estudo é importante destacar a ação do regime militar brasileiro em uma das regiões que foram palco da relação mais tensa entre as sociedade civil 
e o Estado: a Amazônia brasileira, cenário da presença mais viva da intensificação entre o capital nacional e internacional, tendo na implementação dos grandes projetos na região uma das ações mais coercitivas do Estado autoritário.

Os governos militares tentaram implementar no País e, em especial na Amazônia, os acordos originados para reorientação da economia do capitalismo moderno e industrial. A aliança celebrada entre setores do Estado brasileiro colocou o Brasil na fase denominada desenvolvimentista com o discurso de integrar as regiões mais desenvolvidas do Sudeste e Sul do país.

A Amazônia foi espaço de intensa ação autoritária do Estado respaldada no discurso da ocupação, integração e segurança nacional. Lúcio Flávio Pinto (1987), ao analisar as diferentes fases do Estado Nacional na Amazônia, afirma ser este o padrasto da região que garantiu a presença do capital internacional no Brasil por intermédio de várias instituições, entre estas a Superintendência do Desenvolvimento da Amazônia (SUDAM).

Ocupar a Amazônia era a meta orientadora do planejamento dos militares, numa aliança entre as oligarquias da região e frações nacionais do capital, beneficiadas por acordos, concessões, incentivos e isenções fiscais por parte do Estado, o que atraiu grandes empresas do Sul, Sudeste e fora do país. Pinto (1987) também afirma que os efeitos dessa política de incentivos foram drásticos para a região.

A política de ocupação da Amazônia, conforme Alves Filho (2000, p. 50), teve o estímulo governamental e como base fundamental quatro questões: em primeiro lugar, a necessidade de processar a acumulação de capital, aplicando o excedente em atividades produtivas nas grandes metrópoles do mundo. $\mathrm{O}$ autor chama atenção para o fato de que a política de valorização da Amazônia nada mais é que a política de valorização do capital. Em segundo, a transformação da Amazônia em área fornecedora de produtos primários, visando a abastecer o mercado externo e interno. Em terceiro lugar, o objetivo de atingir o mercado internacional fez com que fosse incentivada a produção da carne bovina e, finalmente, em quarto lugar, a ideia de fazer da Amazônia um mercado promissor de consumo de produtos manufaturados do Centro-Sul do país.

Com o incentivo fiscal do governo subsidiando empreendimentos na região, foi salvaguardado o latifúndio e a concentração de renda e terra, uma política sem consideração às populações tradicionais da Amazônia, que sobreviviam da lavoura, como pequenos grupos que desenvolviam a agricultura familiar, índios, negros das comunidades quilombolas e posseiros. Essas populações entraram em confronto direto com as empresas expropriadoras, e o Estado brasileiro garantiu a política modernizadora em favor do latifúndio, segundo Alves Filho: 
[...] o novo modelo transformou a burguesia em proprietária de terra e ávida expropriadora, contribuindo para o surgimento de categorias sociais excluídas e excedentes que migraram para outras áreas dentro da própria Amazônia ou deslocaram-se para os centros urbanos, engrossando os cinturões de miséria das periferias (ALVES FILHO, 2000, p. 51).

O crescimento econômico proclamado pelo governo militar não se refletiu em desenvolvimento efetivo na Amazônia. As ações do Estado foram tímidas em relação à grandeza e à diversidade desta, principalmente o espaço rural, pensado como local puramente para a atividade agropecuária; e a mata, um recurso natural importante, foi derrubada indiscriminadamente, e nada contribuía para a melhoria da qualidade de vida da população.

O campo na Amazônia tem dinâmica própria e seu recurso produtivo necessita de políticas públicas voltadas para o melhor aproveitamento do seu potencial produtivo, como a proteção das nascentes dos rios e reservas naturais. A mata tem uma riqueza natural, mas não pode ser explorada como uma empresa.

O campo na Amazônia ainda tem sua estrutura política assentada na aristocracia rural, no coronelismo, que exerce o poder político na quase totalidade dos municípios, atuando inclusive na gestão pública, usufruindo das benesses dos cargos. Na maioria dos municípios, detecta-se uma sociedade civil frágil, como na maioria do interior do país, com uma população dispersa, com baixo nível organizativo e problema de comunicação em função das dificuldades geográficas e de acesso ao seu interior. Tal cenário é propício ao controle político por pequenos grupos, à improbidade administrativa e à violência no campo.

O Estado, após o golpe militar de 1964, optou no Brasil e, principalmente, na Amazônia por uma política coercitiva, o que impossibilitou a interação e o diálogo entre sociedade civil local e Estado. O governo militar centralizador sufocou por duas décadas as organizações da sociedade civil na região, colocando sob seu domínio aparelhos privados de hegemonia, como sindicatos, partidos, imprensa e as escolas, meio de controle do sistema educacional, do qual é parte a Interiorização das Universidades Federais na Amazônia.

\section{A INTERIORIZAÇÃO DAS UNIVERSIDADES NA AMAZÔNIA: UFPA PIONEIRA NO PROCESSO}

A escola, como instituição, desempenhou hegemonicamente importante papel de aparelho ideológico na Amazônia. A política educacional implementada pela Lei n. ${ }^{\circ}$ 5.540/68, que reformou a Universidade Brasileira, e a Lei n. 5.692/71, para o antigo ensino de $1^{\circ}$ e $2^{\circ}$ graus, foram expressões do interesse dos grupos 
autoritários em transformar o sistema educacional ajustando-o a um projeto desenvolvimentista.

No âmbito da sociedade civil, ou seja, no terreno da disputa ideológica, o governo fortaleceu ou criou instituições que organizaram o regime. Uma dessas instituições foi o Instituto Brasileiro de Ação Democrática (IBAD), que teve suas ações intimamente ligadas à sociedade política, recebendo inclusive estimável financiamento para desenvolver atividades atreladas ao regime autoritário, como o Instituto de Pesquisa e Estudos Sociais (IPES), ao qual coube a responsabilidade de organizar reuniões, estudos e seminários com objetivo de subsidiar gestores para uma política educacional aderente ao projeto autoritário.

O autor Dreifuss (2006) descreve a estrutura política dos interesses do capital nacional e internacional associada à formulação de um bloco civil e militar com intelectuais orgânicos recrutados no empresariado, na tecnoburocracia, na oficialidade militar, que ajudaram intelectualmente na construção de um projeto modernizador e conservador.

O IPES organizou com o MEC as famosas Conferências Nacionais de Educação. Estas significaram o fórum mais privilegiado da política educativa militar, e foi justamente neste espaço que começou a brotar uma das grandes contradições do regime: o questionamento, pelos interlocutores considerados fiéis ao governo, à proposta educacional executada. Esse conflito que exigia a negação da política educacional imposta nada mais era que o germe da exigência do seu contrário, uma nova proposta educativa.

Entre 1965 e 1968, quatro conferências foram organizadas, à exceção da quinta, impedida pelo próprio governo, por temer aflorar no seio desta as divergências dos próprios dirigentes "confiáveis" sobre a política educacional implementada.

A educação como prática social, e integrante das relações travadas no interior do capitalismo, é contraditória. O processo educativo inclui a elaboração do saber, do conhecimento aprimorado, transmite valores, crenças e ideias veiculadas a partir de diretrizes das políticas educativas, sendo o saber elemento importante no processo de gestão do modo de produção capitalista, uma vez que o mesmo será intencionalmente voltado para a produção, direcionando valores para um foco determinado.

O saber como componente fundamental do processo educativo conduz a uma ação pedagógica com base no conhecimento anterior, que em contato com a realidade social se transforma em conhecimento novo, entrando, assim, em contradição com a própria sociedade capitalista. Cury diz que este saber nasce do fazer, e de fazeres diferentes e contraditórios: 
O saber enquanto intenção pode vir a ser apropriado (tornar próprio) pelas classes subalternas. Ao incorporá-lo à sua prática, o torna instrumento de crítica das armas, pois na sua prática (no conjunto das relações sociais) reside a contradição da intencionalidade dominante. (CURY, 2000, p.71).

Na Amazônia, a mobilização social cresceu com a mudança de direção política dos Sindicatos de Trabalhadores Rurais (STR), colônia de pescadores, movimentos de Mulheres Trabalhadoras no Campo e na Cidade. Tais movimentos, fortemente influenciados pelas Comunidades Eclesiais de Base da Igreja Católica e por partidos de esquerda como o Partido Comunista do Brasil (PC do B), Partido Socialista Brasileiro (PSB) e o PT, traziam em seu bojo o desejo de democratização das instituições do Estado, além de influenciar nas políticas públicas de saúde, moradia e educação, em especial o acesso ao ensino superior.

A demanda pelo ensino superior é crescente, sobretudo na zona rural, onde ainda persiste o baixo índice de recursos humanos qualificados e um quadro significativo de professores leigos. Foi na zona rural da Amazônia que se concentrou a importante frente de oposição ao regime militar como a guerrilha do Araguaia $^{3}$, assim como o registro do maior número de mortos e desaparecidos pela ação militar na região, o que fez com que vários municípios fossem considerados área de segurança nacional como Marabá e Santarém, no Pará. A idéia de ocupação e integração recrudesceu como estratégia de controle do espaço geopolítico.

Foi na fase mais dura do regime autoritário que a UFPA iniciou a Política de Interiorização do Ensino Superior no Pará, conforme Resolução n. 39, de 14 de outubro de 1970, que autorizou o Centro de Educação (CED) a criar núcleos de educação em Santarém e Macapá para realização do Curso de Licenciatura Polivalente de $1^{\circ}$ Ciclo.

É importante ressaltar o pioneirismo da UFPA, em especial do Centro de Educação que, para além do campus de Belém, estendeu suas atividades até o município de Benevides no Pará, no processo de interiorização das licenciaturas plenas no interior da Amazônia. Suas ações, mesmo isoladas, excederam o Pará. Tal ação é registrada no documento intitulado A Universidade Federal do Pará: Centro de Educação e a Capacitação de Recursos Humanos, proveniente da coordenação dos cursos de graduação e convênio do Centro de Educação,

Movimento de luta armada formado por jovens estudantes proveniente da região Sul e Sudeste do país. A guerrilha tinha como objetivo na região criar um foco de resistência à ditadura militar. O critério tático de escolha da Amazônia para implementar o foco de resistência levou em consideração por parte dos guerrilheiros, ser a floresta uma importante aliada ao proporcionar obstáculos a força militar. Melhores detalhes consultar: ALVES FILHO. A. dos S. A Política dos Governos Militares na Amazônia (1964-1985). In: Pontos de História da Amazônia. Volume II. ALVES FILHO. A.; SOUZA JUNIOR. A. de; BEZERRA NETO. J. M. Paka-Tatu, 2000. Belém-Pará e DURBENS N. A Guerrilha do Araguaia. 
tendo à frente o técnico Jair Gomes de Araújo que justificou na referida fonte a importância do Centro de Educação no processo interiorização das licenciaturas e a criação de núcleos de educação:

[...] contou-se com núcleo de educação em Santarém (com extensão em Belterra), Castanhal, Bragança, Cametá, Macapá- AP, Rondônia (com extensões em Guajará- Mirim, Ji-Paraná, Cacoal, Pimenta Bueno, Ariquemes, Vilhena), Roraima e Abaetetuba-PA (UFPA, 1993, p. 02).

Essa ação extensionista teve sua origem nos Centros Rurais Universitários de Treinamentos e Ações Comunitárias (CRUTAC), criados em 1965 na Universidade Federal do Rio Grande do Norte (UFRN), com o objetivo de promover estágios, em área rural, aos estudantes, que eram supervisionados por docentes e técnicos.

A proposta idealizada pelo reitor da UFRN, Prof. Onofre Lopes da Silva, foi ampliada para o resto do Brasil por intermédio do Decreto Lei n. ${ }^{\circ}$ 916/69. A concepção extensionista do CRUTAC era de que a Universidade tinha a responsabilidade de levar à população carente não só a orientação em termos de saúde, mas educação cívica, sanitária e planejamento urbano.

O MEC, na época, estava sob o comando do coronel Jarbas Passarinho, que deu total apoio aos CRUTACs e em 1969, segundo o Brasília em dia (2007), o governo ampliou o projeto criando a Comissão Incentivadora dos Centros Rurais Universitários de Treinamento e Ação Comunitária (CINCRUTAC), órgão interministerial (educação, interior, agricultura, saúde, trabalho e previdência social), com a finalidade de expandir a proposta pelo Brasil.

O referido projeto também tinha caráter ideológico, uma vez que o Estado, por intermédio do governo militar, visava manter no interior da Amazônia estudantes universitários em trabalhos de extensão, longe da mobilização política de oposição ao regime, em uma clara tentativa de desbaratar o movimento estudantil e a UNE.

A proposta de extensão do CRUTAC era equivocada desde a sua concepção de extensão universitária; o próprio idealizador do projeto, Prof. Onofre Lopes, tinha o entendimento de que o papel da extensão universitária era levar conhecimento ao povo desprovido de saber, de educação etc., o que Paulo Freire denominou visão extensionista ${ }^{4}$. Nesta concepção a população é vista como inferior,

4 Paulo Freire, em Extensão ou Comunicação, analisa de forma crítica o papel da extensão desde o sentido, contexto e significado desta palavra. Um dos sentidos analisados por Freire é de que extensão indicaria a ação de "estender algo à", de transmitir alguma coisa a alguém que não tem, que é carente de algo, transformando a extensão em prática extensionista, na qual o trabalho é tentar fazer com que aqueles substituam seus conhecimentos, associados a sua ação sobre a realidade, por outros. E estes são conhecimentos extensionistas (1992, p. 24). 
E todos esses termos envolvem ações que, transformando o homem em quase "coisa", o negam como um ser de transformação do mundo. Além de negar, como veremos, a formação e a constituição do conhecimento autênticos. Além de negar a ação e a reflexão verdadeiras àquelas que são objetos de tais ações. (FREIRE, 1992, p. 22).

A visão elitista de extensão universitária propagada pelos governos militares contribuiu não só para disseminar o preconceito contra o homem e a mulher rural, mas também aprofundou a cisão entre campo e cidade. Tal concepção cultivou no imaginário das pessoas a visão estereotipada de que a população campesina não tem cultura, seu trabalho no campo carece de aprimoramento ou planejamento, cabendo ao intelectual, com sua cultura erudita, orientá-lo.

A década de 1980 foi sacudida por forte mobilização social, o regime militar chegou à exaustão em 1986, a sociedade brasileira continuava o processo de construção da democracia, de nova concepção de mundo e cidadão. A independência dos movimentos sociais ante o Estado e seu aparato organizativo refletiram na sociedade e nas instituições, a exemplo da universidade, quebrando paradigmas em termos de cultura, saúde e educação. Neste processo de mudança paradigmática no âmbito epistemológico, brotou também uma nova concepção de extensão universitária, construída no interior de diversos fóruns, inclusive institucionais, como o Fórum de Pró-Reitores de Extensão.

O MEC e o Fórum de Pró-Reitores de Extensão das Universidades Públicas construíram o Plano Nacional de Extensão, lançado inicialmente em 1999. Este plano foi elaborado pela Coordenação Nacional do Fórum, gestão 1998/1999, e apresenta o conceito, a concepção e os princípios básicos de extensão universitária, o que se contrapõe frontalmente à proposta do CRUTAC. A nova concepção de extensão rompe com o assistencialismo, passando a questionar as ações desenvolvidas pela própria extensão. Esse processo construiu um novo conceito de extensão que, segundo o Plano Nacional, diz que

A Extensão é uma via de mão-dupla, com trânsito assegurado à comunidade acadêmica, que encontrará, na sociedade, a oportunidade de elaboração da práxis de um conhecimento acadêmico. (PLANO NACIONAL DE EXTENSÃO UNIVERSITÁRIA, 2001, p. 04)

\section{CONCLUSÃO}

A concepção de extensão universitária atual possibilita imprimir uma nova face à universidade brasileira, fazendo-a capaz de promover mudança na sociedade. Tanto a concepção como seus instrumentos amadureceram, foram 
aperfeiçoados e a universidade pública brasileira se apresentou com nova roupagem para dialogar com a sociedade.

Concluiu-se, a partir desta breve análise da atuação do Estado na Amazônia e o comportamento da sociedade civil diante das investidas deste, ser possível levantar uma hipótese explicativa com alicerce sólido, que persiga o caminho que apontamos ser a tese da origem da política de interiorização das Universidades Federais da Amazônia. Nossas reflexões e hipóteses apontam que a interiorização das Universidades Federais da Amazônia se desenvolveu enquanto política a partir de dois momentos ${ }^{5}$.

$\mathrm{O}$ primeiro momento tem sua origem vinculada à proposta do Estado Desenvolvimentista conforme foi demonstrado, localizando no CRUTAC e nos campi avançados a gênese da política, sendo a UFPA, por intermédio do Centro de Educação, sujeito importante do referido processo.

O segundo momento situa-se na "Nova República", com a articulação das Instituições Federais de Ensino Superior (IFES) da Amazônia brasileira em torno dos Projetos Norte de Interiorização (PNI). O I PNI (1986 a 1989), o II PNI (1994 a 1997) e o III PNI (1998 a 2001).

Destacou-se que, a partir do governo Fernando Henrique, a interiorização sofreu influência da reformulação da Constituição Federal publicada no Diário Oficial da União (DOU) em 13 de julho de 1996, com a denominada Emenda 14, que estabeleceu a lei no 9424, Lei do FUNDEF (Fundo de Manutenção e desenvolvimento do Ensino Fundamental e Valorização do Magistério).

O FUNDEF permitiu que os prefeitos firmassem convênio com as universidades, com o objetivo de estas oferecerem aos docentes das redes de ensino municipal a formação superior exigida pela LDB - Lei n. ${ }^{\circ}$ 9394/96, o que resultou na modificação do formato implementado no projeto de interiorização tradicional- PNI.

Observou-se que as Universidades da região amazônica, e em especial a UFPA, se anteciparam à própria Constituição Federal de 1988, que no caput do artigo 60 da primeira versão dizia que nos dez primeiros anos da promulgação da Constituição, as IFES deveriam descentralizar suas funções com o objetivo de atender cidades com maior densidade populacional, cuja média era de 60 mil habitantes. Esse artigo, antes mesmo de completar 10 anos, sofreu alteração pela Emenda 14/1996, que estabeleceu o Fundo de Manutenção e Desenvolvimento do Ensino Fundamental e de Valorização do Magistério (FUNDEF). A modificação no artigo 60 ficou assim:

5 Os detalhamentos de cada momento aqui desenhado serão aprofundados em próximo artigo, dando assim prosseguimento a nossa pesquisa. 
Art.60. Nos dez primeiros anos da promulgação da Constituição, o Poder Público desenvolverá esforços, com a mobilização de todos os setores organizados da sociedade e com a aplicação de, pelo menos, cinqüenta por cento dos recursos a que se refere o art. 212 da Constituição, para eliminar o analfabetismo e universalizar o ensino fundamental.

Parágrafo único. Em igual prazo, as universidades públicas descentralizarão suas atividades, de modo a estender suas unidades de ensino superior às cidades de maior densidade populacional (BRASIL, 1988, p. 200).

Com a Emenda 14 em vigor, o governo federal passou a contribuir financeiramente com os municípios, proporcionando às várias prefeituras a utilização do referido recurso em prol da formação de professores. Muitos convênios foram firmados entre gestão municipal e universidades, desencadeando o terceiro momento da interiorização, no qual o projeto inicial se manteve com muita dificuldade, em campi onde havia estrutura física herdada do projeto Rondon, como os de Altamira, Santarém e Marabá, o que possibilitou manter os cursos de licenciatura plena em Pedagogia, Matemática e Letras em caráter regular. Destino diferente tiveram os campi menores, como Bragança, Breves, Soure, Cametá, Abaetetuba e Castanhal, que lutaram para não serem extintos em consequência do sucateamento ao qual foi submetida a universidade brasileira no governo Fernando Henrique Cardoso.

Há que se destacar que no governo de Luiz Inácio Lula da Silva a interiorização da UFPA serviu de modelo para a implementação de outros Campi em diversas regiões do país, em especial no Nordeste, e com o Programa de Apoio a Planos de Reestruturação e Expansão das Universidades Federais (REUNI) foi possível a consolidação da política de interiorização da UFPA para os rios e florestas do campo paraense, uma vez que os campi estão sendo totalmente reformados, o que resultou em uma série de concursos públicos para admissão em cargo efetivo de docentes. O campus de Santarém transformou-se na mais nova universidade e, desta vez, localizada na zona rural, a Universidade Federal do Oeste do Pará (UFOPA), o que significou um grande avanço, além dos desdobramentos com sucesso de uma exitosa política pública de interiorização das IFES, voltada para a educação em nível superior dos filhos de camponeses e ribeirinhos, configurando-se como uma grande política de inclusão social. 


\section{REFERÊNCIAS}

ALVES FILHO, A. A Política dos Governos Militares na Amazônia (1964-1985) In: ALVES FILHO, A; SOUZA JR, J. A. de; BEZERRA NETO, J. M. B. Pontos de História da Amazônia. v II. 2 ed. Rev. Ampl. Belém: Paka-Tatu, 2000.

BRANDÃO JUNIOR, H.; MEDEIROS, A. C. Em Busca de Novos Paradigmas para a Análise de Políticas Públicas. Revista Administração Pública, Rio de Janeiro, v. 24, n.3, p. 4-53, maio-jul., 1990..

BRASIL. Constituição da República Federativa do Brasil. São Paulo: Ática, 1988.

BRASIL. Fórum de Pró-Reitores de Extensão das Universidades Públicas Brasileiras e SESu / MEC. Plano Nacional de Extensão Universitária. Brasília, DF:Senado Federal, 2001.

BRASIL. MEC-Ministério da Educação. Programa de Expansão do Sistema Federal de Educação Superior (REUNI). Disponível em: <http://www. portal.mec.gov.br/sesu>. Acesso em: 4 jun. 2007.

COHEN, J.; ARATO, A. Sociedad Civil y Teoria Política. Mexico: Fondo de Cultura, 2000.

COHEN, J. L.; ARATO, A. Civil Society and Political Theory. Cambridge, MA: MIT Press, 1994.

COSTA, S. As Cores de Ercília: Esfera Pública, Democracia, Configurações Pós-Nacionais. Belo Horizonte: UFMG, 2002.

COUTINHO, C. N. Marxismo e Política: a dualidade de poderes e outros ensaios. São Paulo: Cortez, 1996.

COSTA, F. de A. Indicadores de prioridade para políticas públicas dirigidas ao desenvolvimento sustentável na Amazônia. Novos Cadernos NAEA, Belem, v. 3, n. 1 - p. 101-118, jan.-jun. 2000.

CURY, C. R. J. Educação e Contradição. São Paulo: Cortez, 2000.

DREIFUSS, R.A. 1964: a conquista do Estado: ação política, poder e golpe de classe. Petrópolis: Vozes, 2006.

DURIGUETTO, M.L. Sociedade Civil e Democracia: um debate necessário. São Paulo: Cortez, 2007.

FREIRE, P. Pedagogia da esperança. São Paulo: Paz e Terra, 1992

GRAMSCI, A. Os intelectuais e a organização da Cultura. Tradução de Carlos Nelson Coutinho. Rio de Janeiro: Civilização Brasileira, 1988. 
Caderno do Cárcere n. ${ }^{\circ}$ 12. Revisão da Tradução Paolo Nosella. Florianópolis: UFSCAR, 1989.

LIGUORI, G. Roteiros para Gramsci. Tradução Luiz Sérgio Henriques. Rio de Janeiro: UFRJ, 2007.

MARX, K.; ENGELS, F. A Ideologia Alemã. São Paulo: Hucitec, 2002.

MARX, K.; ENGELS, F. O Manifesto comunista. 9. ed. Petrópolis: Vozes, 1999

PINTO, L. F. O Estado Nacional: Padrasto da Amazônia. Pará Desenvolvimento, Belém, n. 20/21, p. 3-6, jan./jun.-jul./dez. 1987.

RESTREPO, L. A. A relação entre a sociedade civil e o Estado: elementos para uma fundamentação teórica do papel dos movimentos sociais na América Latina. Tempo Social, São Paulo, v. 2, n. 2, p. 61-100, 1990.

SUDAM-Superintendência do Desenvolvimento da Amazônia. Projeto Norte de Interiorização" e Sistema de Informação Científica e Tecnológica da Amazônia - INFORMAM. Proposta de Trabalho da Coordenação de Educação e Desenvolvimento Regional Belém: SUDAM, 1987.

UFPA-Universidade Federal do Pará. I Projeto Norte de Interiorização: Documento das Instituições de Ensino Superior da Amazônia, 1986-1989: Belém: UFPA, [s.d.].

UFPA-Universidade Federal do Pará. Resolução $\mathbf{n}^{\circ}$ 39, de 14 de outubro de 1970. Dispõe sobre a criação de Núcleos de Educação em Santarém e em Macapá para criação de cursos de Licenciatura Polivalente de $1^{\circ}$ ciclo. Belém: UFPA, 1970.

UFPA-Universidade Federal do Pará. A Universidade Federal do Pará: Centro de Educação e a Capacitação de Recursos Humanos. Belém: UFPA, 1993. Mimeo.

UFPA-Universidade Federal do Pará. (1993). II Projeto Norte de Interiorização: Documento das Instituições de Ensino Superior da Amazônia, 1994-1997. Santarém: UFPA, 1993. Mimeo.

UFPA-Universidade Federal do Pará. Centro de Educação. Vagas Docentes para o Projeto de Interiorização. Belém: FPA/IE, 1996. Mimeo.

UFPA-Universidade Federal do Pará. (1997). III Projeto Norte de Interiorização: Documento das Instituições de Ensino Superior da Amazônia, 1998- 2001. Belém: ufpa, 1997. Mimeo. 